\section{Optical Rotatory Dispersion of Amino Acid Methylthiohydantoin}

\section{Tateo Suzuki and Katura Tuzimura}

Laboratory of Analytical Chemistry, Department of Food Chemistry,

Faculty of Agriculture, Tohoku University,

Tsutsumidori-Amamiyamachi, Sendai

Received September 20, 1972

Djerassi and others ${ }^{11}$ studied the optical rotatory dispersion (ORD) of some amino acid phenylthiohydantoins which partially retained their optical activities.

Recently, amino acid methylthiohydantoin (MTH) has been studied for peptide sequence determination in the place of phenylthiohydantoin. In this paper, we report ORD of MTHs, and discuss the chromophore contribution by the reference of ultraviolet spectrum.

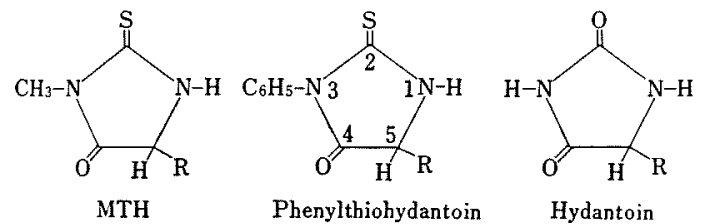

( $R$ : derived from the side chain of amino acid)

Nineteen amino acid MTHs were prepared. Six MTHs derived from alanine, valine, leucine, isoleucine, phenylalanine, and lysine retained their optical activities (Figs. 1 and 2). Ten MTHs of methionine, tyrosine, cysteine, aspartic acid, glutamic acid, asparagine, glutamine, arginine, histidine and proline, racemized and showed no optical activities in these conditions. Serine, threonine and tryptophan were avoided from measurement, which decomposed and colorized.

Rotatory dispersions were measured in $10^{-2}$ mole/ liter (ca. $0.1 \sim 0.3 \%$ ) ethanol or water solution (Instrument; JASCO model ORD/UV-5. Temperature; $24 \sim 28^{\circ} \mathrm{C}$ ).

1. Chromophore contribution of MTHs. The ultraviolet spectrum of alanine MTH had the high intensity absorption at $268 \mathrm{~nm}(\log \varepsilon=4.16)$ and very weak shoulder at $c a .300 \mathrm{~nm}(\log \varepsilon=1.00)$ (Fig. 3). These absorptions might be assigned respectively the $\pi \rightarrow \pi^{*}$ and $n \rightarrow \pi^{*}$ transition of thiocarbonyl group, since the spectrum of thiourea gives the similar curve. Wavelength of CD peaks of MTHs which appeared between 303 and $312 \mathrm{~nm}$ agreed with the shoulder of the UV spectrum.

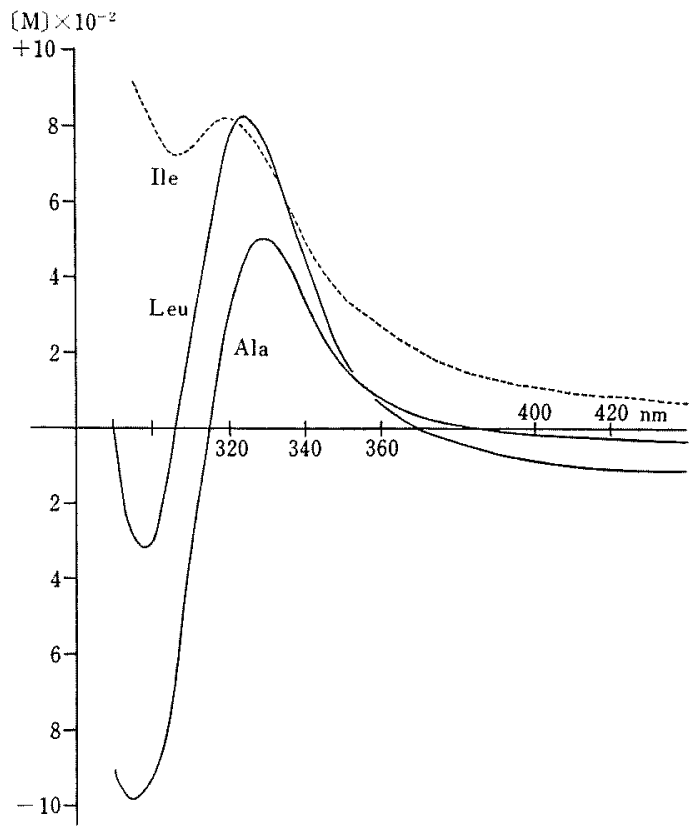

FIG. 1. ORD of MTHS (I)

Alanine, leucine and isoleucine

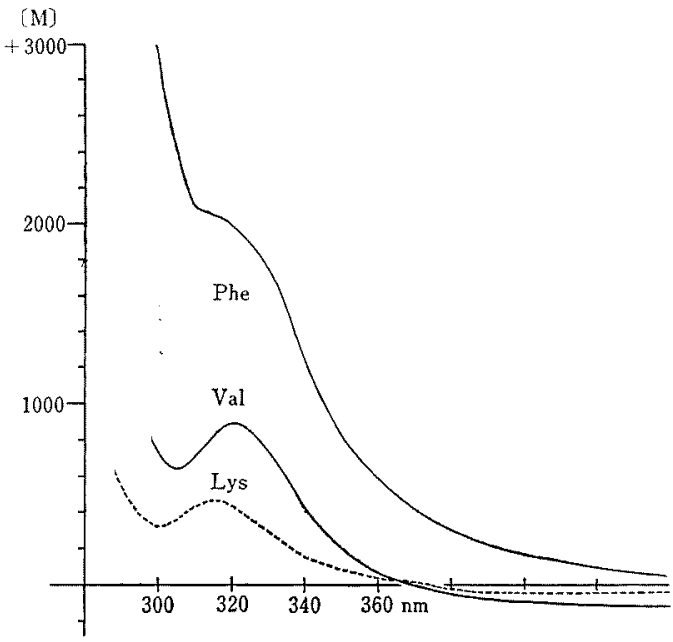

FIG. 2. ORD of MTHs (II).

Valine, phenylalanine and lysine

Djerassi and others discussed that the rotatory dispersion of phenylthiohydantoins might be caused by the $n \rightarrow \pi^{*}$ transition of thiocarbonyl group at $300 \mathrm{~nm}$. Rotatory dispersion of MTHs, therefore, may arise from the $n \rightarrow \pi^{*}$ transition of thiocarbonyl group at $\mathrm{C}-2$.

2. The loss of activity. Methylthiohydantoins racemized in methanol contained hydrogen chloride 


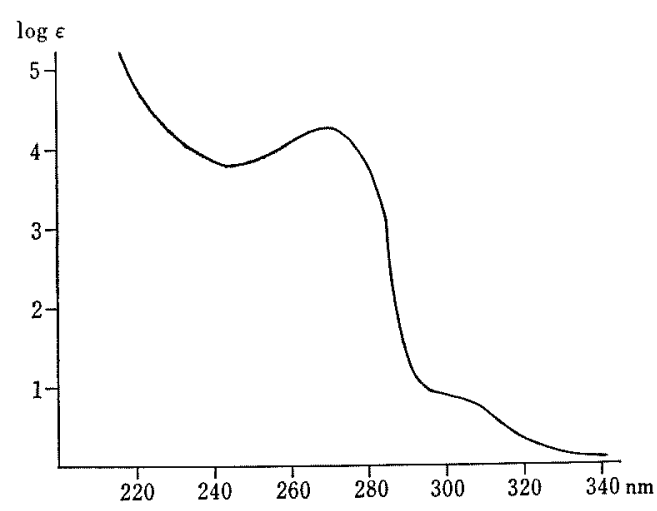

FIG. 3. UV Spectrum of Alanine MTH.

Table I. CD MaXima of Amino Acid MTHs

\begin{tabular}{llc}
\hline \multicolumn{1}{c}{ MTH } & $\lambda_{\max }$ & {$[\theta]$} \\
\hline Ala & $312 \mathrm{~nm}$ & +1305 \\
Val & 308 & +1430 \\
Leu & 307 & +1865 \\
Ile & 307 & +2760 \\
Phe & 310 & +1700 \\
Lys & 303 & +730 \\
\hline
\end{tabular}

even at room temperature (Fig. 4).

Edman $^{21}$ reported that the specific rotations of phenylthiohydantoins at sodium D-line $(589 \mathrm{~nm})$ were either $0^{\circ}$ or very low, in spite of the optical activities of the corresponding amino acids. He also assumed that the racemization may caused by the electron attracting phenyl group attached to N-3 of thiohydantoin ring. Edman's speculation about phenylthio- hydantoin was not correct, since amino acid MTH, which had electron donating methyl group at $\mathrm{N}-3$ instead of phenyl group, also easily lost their optical activities.

The authors assumed that there are predominantly two causes for racemization.

a) Tautomerization. Hydantoin ring series

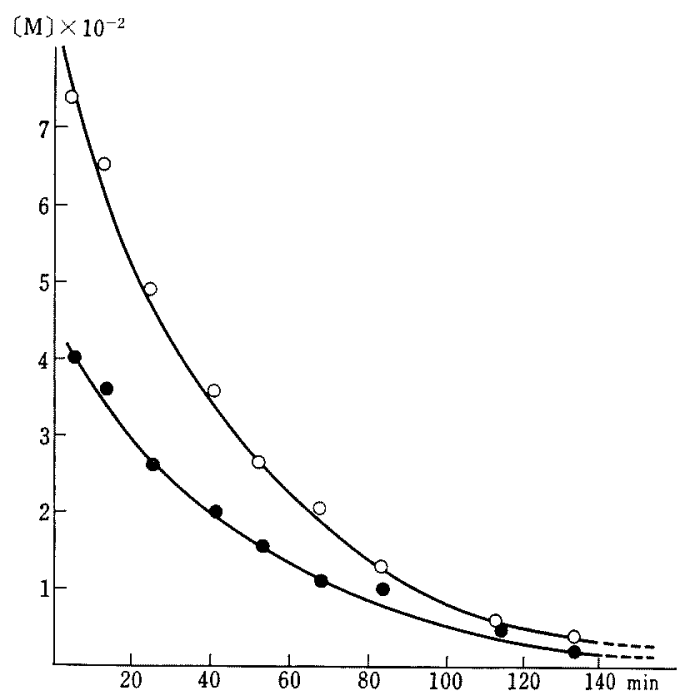

FIG. 4. Racemization of L-Leucine MTH in MeOH. Chart was obtained in methanol contained $6 \mathrm{~N}$-hydrogen chloride and a few drops of water at room temperature.

$\mathrm{O}-\mathrm{O},[\mathrm{M}]_{324 \mathrm{~nm}}^{26^{\circ} \mathrm{C}}(\max ,+$ value $) ; \bullet-,[\mathrm{M}]_{300 \mathrm{~nm}}^{26^{\circ} \mathrm{C}}(\mathrm{min}$, - value)

TABLE II. [M] OF MTHs

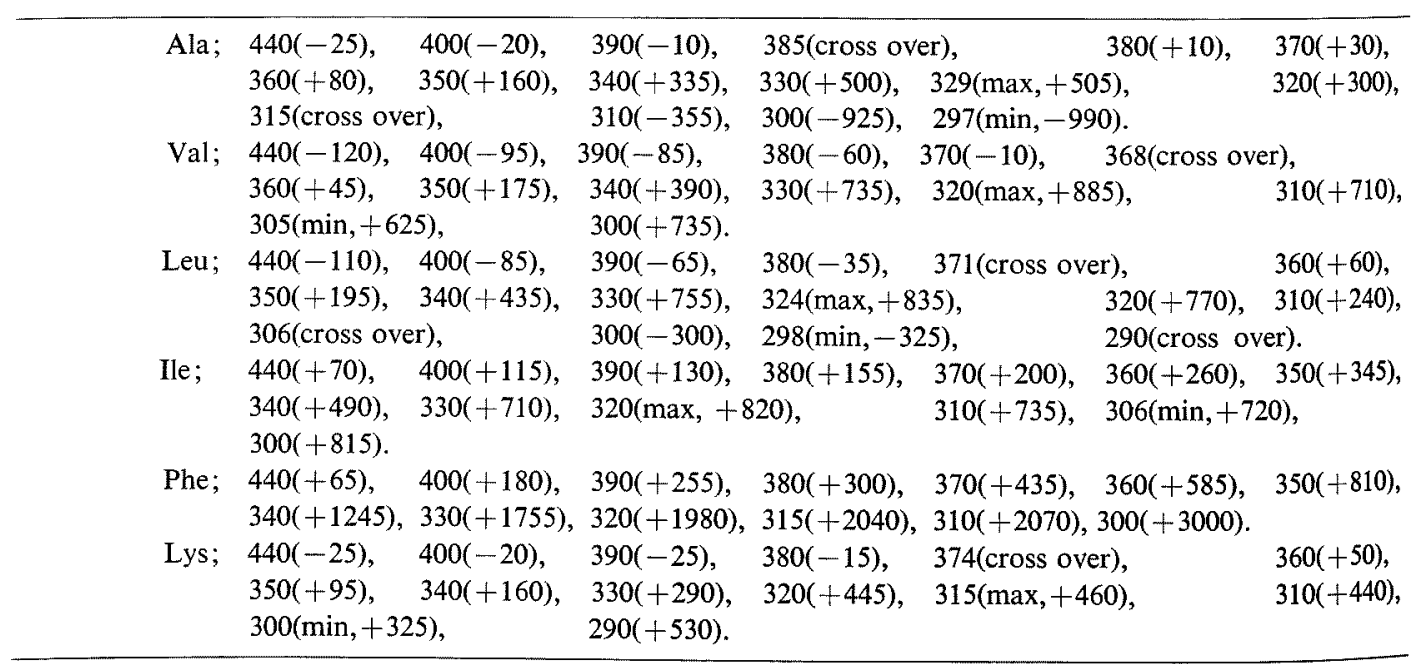

Wavelength $\mathrm{nm}([\mathrm{M}])$. 
tautomerize generally. MTH may racemized by the deprotonation as the result of thioketo-thiol tautomerization. It seems that thiocarbonyl group at C-2 causes predominantly for racemization, since amino acid hydantoins, which have carbonyl group at $\mathrm{C}-2$, do not racemize and retain their optical activities. ${ }^{3+}$

b) Thermal racemization. Methylthiohydantoin, which is cyclized in the room temperature, tends to retain its optical activity. Whereas it tends to racemize almost completely by refluxing, though tautomerization proceeds simultaneously in the acidic catalyst.

Authors assume that the racemization mainly occur by the tautomerization with thiocarbonyl group. The acidic catalyst and the elevated temperature accelerate the racemization, since optical activity of amino acid hydantoins retains in spite of refluxing in hydrochloric acid.

\section{REFERENCES}

1) C. Djerassi, K. Undheim, R. C. Sheppard, W. G. Terry and B. Sjöberg, Acta Chem. Scand., 15, 903 (1961).

2) P. Edman, ibid., 4, 277 (1950).

3) T. Suzuki, K. Igarashi, K. Hase and K. Tuzimura, Agr. Biol. Chem., 37, 411 (1973). 